\title{
ESTRUTURA E DESIGN ORGANIZACIONAL
}

Os estudos e debates envolvendo as questões sobre estrutura e design organizacional vêm desenvolvendo-se a partir de duas perspectivas distintas: a primeira, própria do projeto modernista de organização, procura discutir as novas alternativas de estrutura e design organizacional diante de um ambiente altamente turbulento e competitivo; a segunda, relacionada à proposta pós-modernista ou da teoria crítica, trata do tema como a manifestação de diferentes formas de se entender as organizações. Dentro dessa abordagem, as novas formas organizacionais representam a operacionalização de modos de racionalidade diferentes daquele descrito por Weber como típico do modelo burocrático. Esta seleção, realizada pela professora Eloise Livramento Dellagnelo, da Universidade Federal de Santa Catarina, apresenta alguns trabalhos relevantes produzidos no âmbito acadêmico.
MODERN ORCANIZATIONS

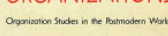
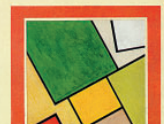

Stewart R. Clegg
MODERN ORGANIZATIONS: organization studies in the postmodern world

Stewart R. Clegg. London : Sage, 1990. 261 p.

Esse livro é um marco significativo nas discussões sobre pós-modernismo em termos de evidências empíricas. Clegg deixa clara a conexão entre modos de racionalidade e diferentes dimensões organizacionais e procura definir um quadro de análise comparativo entre organizações modernas e pós-modernas. Cabe destacar a ênfase dada pelo autor para a idéia da racionalidade ou uma perspectiva mais cultural na análise organizacional, sem dúvida, uma contribuição fundamental em toda a discussão abrangendo o tema.

BUILDING THE FLEXIBLE FIRM: how to remain competitive

Henk W. Volberda. New York : Oxford University Press, 1998. 349 p.

Esse trabalho tem grande valor pela capacidade de síntese das diferentes dimensões que envolvem os novos designs organizacionais. Cabe observar que, apesar de o autor advogar que a abordagem apresentada seja típica de organizações pós-modernistas e, por conseqüência, própria de uma racionalidade substantiva, o desdobramento de seu trabalho deixa dúvidas a respeito. De fato, o tratamento dado à flexibilidade, do ponto de vista da tecnologia, estrutura e cultura, evidencia a possibilidade da concretização de burocracias flexíveis, e não necessariamente modelos alicerçados em uma racionalidade não instrumental.
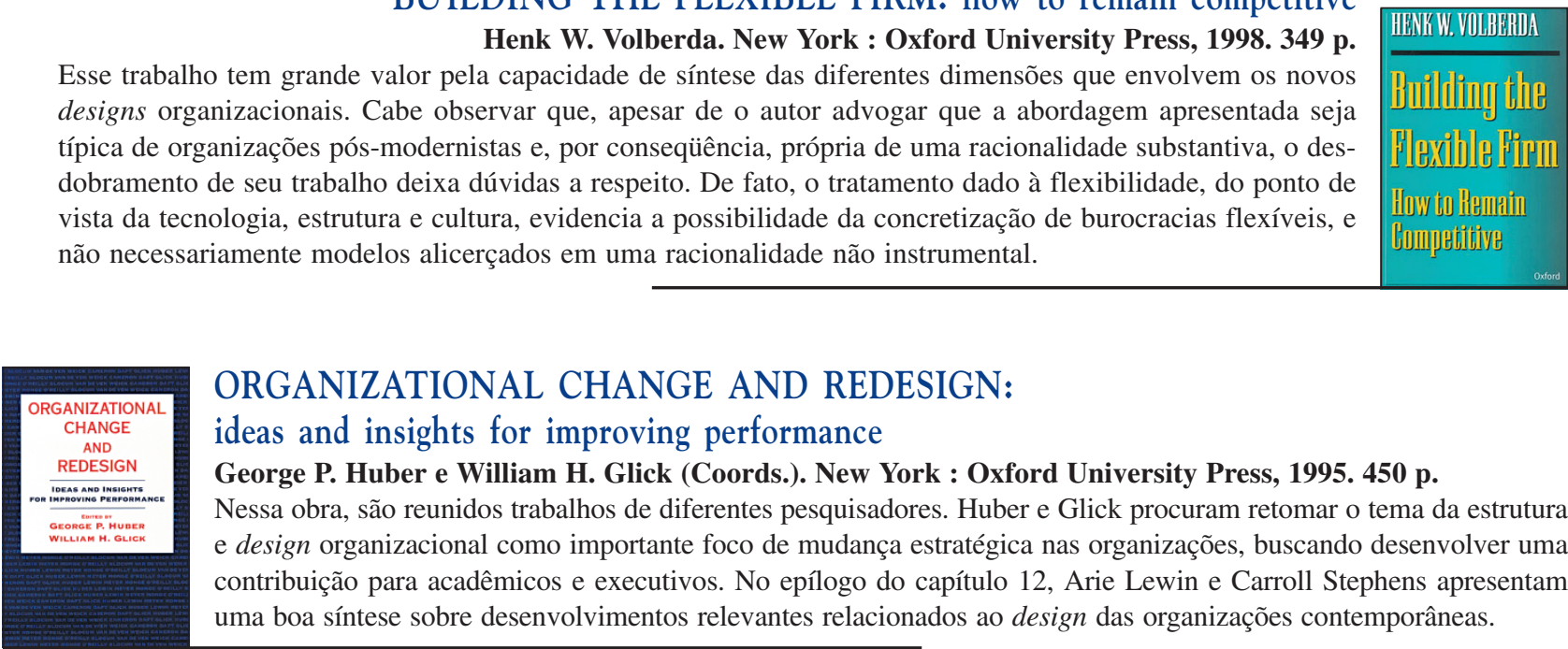

ORGANIZATIONAL CHANGE AND REDESIGN:

ideas and insights for improving performance

George P. Huber e William H. Glick (Coords.). New York : Oxford University Press, 1995. 450 p.

Nessa obra, são reunidos trabalhos de diferentes pesquisadores. Huber e Glick procuram retomar o tema da estrutura e design organizacional como importante foco de mudança estratégica nas organizações, buscando desenvolver uma contribuição para acadêmicos e executivos. No epílogo do capítulo 12, Arie Lewin e Carroll Stephens apresentam uma boa síntese sobre desenvolvimentos relevantes relacionados ao design das organizações contemporâneas.

\section{ORGANIZANDO PARA COMPETIR NO FUTURO: estratégia para gerenciar o futuro das organizações}

Jay R. Galbraith, Edward E. Lawler III e Associados. São Paulo : Makron Books, 1995. 287 p. Esse livro é uma coletânea de uma série de trabalhos fundamentados em pesquisas realizadas pelo Center of Effective Organizations, da Universidade do Sul da Califórnia. A obra trata de temas específicos como trabalho em equipe, empowerment, liderança, relação entre estrutura e estratégia, unidade de negócios, etc. Não apresenta o tom prescritivo dominante em literatura semelhante.

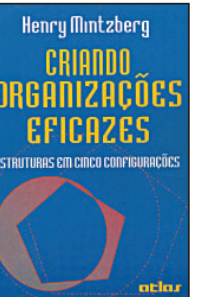

CRIANDO ORGANIZAÇÕES EFICAZES: estruturas em cinco configurações Henry Mintzberg. São Paulo : Atlas, 1995. 304 p.

Esse trabalho aborda, de forma clara e objetiva, questões básicas da estruturação das organizações e questões importantes para a compreensão das mudanças que o design organizacional vem assumindo nos últimos tempos. De maneira competente, Mintzberg trata da relevância da relação do design com a eficácia organizacional. O papel da coordenação dos sistemas organizacionais é enfatizado e, dependendo de sua caracterização, diferentes configurações são estabelecidas. 